\title{
Comparación de factores psicosociales de riesgo en adolescentes de Bucaramanga y su área metropolitana en función del género
}

\author{
Ana Fernanda Uribe Rodríguez ${ }^{1}$ \\ Diana Lyzeth Carreño Arango ${ }^{2}$ \\ Milena Espinosa Jurado ${ }^{3}$ \\ Luz Elizabeth Sastoque Jerez ${ }^{4}$
}

\begin{abstract}
Resumen
En Colombia, el panorama del VIH/SIDA es preocupante, pues cada año las cifras de nuevos casos se registran en aumento. Santander por su parte, cuenta con muy poca información sobre estadísticas y grupos poblacionales de riesgo, por consiguiente la presente investigación realiza aportes relevantes en torno a los conocimientos, actitudes y percepción de susceptibilidad y autoeficacia en los adolescentes de Bucaramanga y su área metropolitana. Los hallazgos revelan que el desconocimiento es el principal factor de riesgo de los adolescentes frente a la infección por VIH. Por su parte la actitud positiva aparece como predominante y la percepción de susceptibilidad y autoeficacia de los adolescentes entrevistados puntúan altas en estas variables, lo cual podría actuar como factor protector.
\end{abstract}

Palabras clave: adolescentes, VIH/SIDA, conocimientos, actitudes, susceptibilidad y autoeficacia. 


\title{
Comparison of psychological risk factors in teenagers of Bucarmanga and it's metropolitan area according sex genre
}

\begin{abstract}
In Colombia, each year there are increasing numbers in new cases of HIV/AIDS and the researches are showing their interest in this issue. Santander, has Little information about statistics and risk population group, therefore, the present research made important contribution about knowledge, attitudes and perception of susceptibility and selfefficacy in teenagers of Bucaramanga and metropolitan area. The findings show that the ignorance of the teenagers is the main risk factor for HIV infection. The positive attitude high scores and the teenagers express acceptance towars people infected. Susceptibility and self efficacy, the teenagers show that could perform behaviors of protection.
\end{abstract}

Keywords: Teenagers, HIV/AIDS, Knowledge, Attitudes, Susceptibility and Self efficacy.

Recibido: 23/09/2014

Aceptado: 17/11/2014

\section{lntroducción}

Hace más de treinta años se conocieron los primeros casos de VIH; a partir de ese momento múltiples organizaciones y disciplinas del área de la salud de todos los continentes han puesto sus esfuerzos para evitar la propagación de la enfermedad, mejorar la calidad de vida o el estado de salud de las personas que la padecen, aumentar el tiempo de vida mediante el acceso al tratamiento antirretrovírico y por último, como expone Sidibé en el informe de Onusida (2011), mantener «la visión de un mundo en el que no se produzca ni una sola infección por el VIH, libre de discriminación y donde nadie muera como consecuencia del Sida» (p.5); a pesar de ello, el VIH/Sida continua siendo un grave problema de salud pública en el mundo, principalmente en países de ingresos bajos o medios (Organización Mundial de la Salud -OMS-, 2011). Así pues, investigar sobre VIH/SIDA constituye la realización de aportes en uno de los temas con mayor tendencia en la actualidad y cuyos resultados pueden aportar datos significativos para la planeación de estrategias de prevención e intervención en salud sexual y reproductiva. 
A escala mundial, desde 1997 hasta el 2010, ha disminuido en un 21\% el número de nuevos casos anuales de infección por VIH, aun siendo 1999 el año en el cual la epidemia del VIH alcanzó su punto máximo a nivel global. A finales del 2010, aproximadamente un 17\% más de personas en el mundo vivían con la enfermedad en comparación con el 2001, en parte como resultado de la ampliación en el acceso al tratamiento antirretrovírico, especialmente en países de bajos y medianos ingresos, lo que se traduce en menos muertes por Sida. Para el año 2000, las muertes relacionadas con el Sida alcanzaron un nivel máximo de 2,2 millones, estadística que disminuyó a 1,8 millones para el año 2010 (Onusida, 2011).

Es así como la epidemia del VIH se ha estabilizado desde el año 2000, lo que refleja un descenso en la cantidad de personas infectadas por el virus, siendo esta disminución más evidente en algunas regiones del mundo, como lo es en África subsahariana, caracterizada por tener el mayor volumen de personas que viven con VIH, seguido del Caribe que tiene la segunda prevalencia regional más alta de $\mathrm{VIH}$, en donde se presentó una desaceleración de esta infección como consecuencia de la prestación de servicios de prevención. Para América Latina, descendió el número de muertes por VIH, como resultado del tratamiento antirretrovírico que reciben las personas infectadas; de este mismo modo hubo descenso considerable en la aparición de nuevos casos (Onusida, 2011). Estas tendencias favorables no se presentan uniformemente dentro de las regiones, ni entre las regiones, además presentan cambios en función del grupo de edad. Los adolescentes constituyen una de las poblaciones más vulnerables para contraer la infección; se reportó que el número de nuevos casos superó las 7.000 infecciones diarias en el 2009; cerca de 6.000 casos se presentan en personas mayores de 15 años, de los cuales el $41 \%$ corresponde a jóvenes entre los 15 y 24 años, este rango de edad representa el mayor número de nuevos casos diagnosticados por VIH en el mundo (Onusida, 2010).

Así mismo, se encuentran diferencias en función del género, las estadísticas arrojan que de los 7.000 nuevos casos diarios por VIH a nivel mundial, el 51\% pertenecen al género femenino (Onusida, 2010); por su parte el Ministerio de la Protección Social (2010) señala que en Colombia, en el 2009 «se reportaron 6.780 personas con VIH/Sida y fallecidos, de los cuales 4.664 fueron hombres $(68,8 \%)$ y 2.116 mujeres $(31,2 \%) »$ lo cual indica que la prevalencia por VIH es aún mayor en los hombres «a excepción del grupo de edad entre los 15 a 19 años en el cual existe predominio femenino»(p.22). El género demuestra diferencias en función de la autoeficacia y la actitud neutra de los adolescentes evidenciadas en el hecho de que los varones se sienten más autoeficaces frente al virus en Colombia, especialmente los pertenecientes a la región insular, en cambio en las mujeres predomina la actitud neutra frente a la infección en relación a los hombres, es decir, tienen mayor asertividad ante las personas diagnosticadas (Uribe, 2005; Uribe, Valderrama, Sanabria, Orcasita y Vergara, 2009). Ahondar sobre esta variable diferencial podría ser determinante para establecer planos 
de acción, que posibiliten desarrollar herramientas de intervención de manera centralizada (según el género), estableciendo estrategias efectivas de acción para la prevención de riesgo y el fortalecimiento de los factores de protección.

En Colombia desde la primera aparición de la enfermedad hasta el 2009 «se reportó un total de 71.509 casos notificados de infección por VIH, casos en estadio de sida y fallecidos» (Ministerio de la Protección Social, 2010, p.20). Para el 2008, la Cruz Roja determinó que el $0.7 \%$ de la población vivía con $\mathrm{VIH}$, de los cuales 160 mil son hombres y 45 mil son mujeres y añaden que de cada cinco casos de VIH, uno padece la enfermedad de SIDA, ubicando las poblaciones más vulnerables en las zonas del Caribe y el Pacifico.

Teniendo en cuenta el panorama, se hace precisa la búsqueda de los posibles factores que exponen en mayor medida al adolescente frente a la probabilidad de contraer la infección del VIH. Además es importante conocer los pensamientos que tienen los jóvenes y las conductas que predominan en su vida sexual y reproductiva, de modo que los diferentes profesionales puedan orientar sus esfuerzos en diseñar estrategias que logren reducir la tasa de adolescentes infectados y aumentar el nivel de conocimientos en los mismos, interviniendo en el desarrollo de habilidades que le permitan al adolescente enfrentar satisfactoriamente las diferentes situaciones psicosociales a las que se enfrentan a diario, es decir, por un lado se busca resaltar la importancia de prevenir el riesgo de infección, y por otra parte, se pretende implementar, identificar y fortalecer conductas de protección frente a la misma situación.

Con respecto a los factores que intervienen en la prevención y aparición de la enfermedad en los adolescentes, es preciso describir cada uno de ellos para facilitar la comprensión del fenómeno. En cuanto a los conocimientos, estos son considerados como un factor de protección frente al VIH e incluyen información sobre las medidas de prevención y protección, las ideas sobre la infección y las distintas formas de transmisión. En la investigación realizada por Cortés, García, Fullerat y Fuentes (2000), se plantea que «la ignorancia es un factor que favorece la aparición de Enfermedades de Transmisión Sexual» (p.9), es decir, el desconocimiento sobre los diferentes factores relacionados con la adquisición del VIH, puede llevar a la ejecución de prácticas sexuales riesgosas y conductas que atenten contra el bienestar físico y emocional del adolescente. A su vez González (2009), afirma que «el 80\% de los jóvenes mantiene su primera relación sexual sin protección (y no es planeada), a pesar de que la mayoría obtuvo información acerca del SIDA o métodos anticonceptivos antes de iniciar su vida sexual» (p.15). Otros estudios realizados por Castillo, Extremera, León \& Naranjo (2003), señalan que el desconocimiento conduce a la presencia de diversas conductas de riesgo como el inicio cada vez más temprano de las relaciones sexuales, el cambio de pareja continuo y la falta generalizada del uso de medios de protección. Ahora bien, en la investigación realizada por González, Núñez, Couturejuzon y Ambrós (2005), los resultados indican que las ideas 
incorrectas frente al VIH/SIDA en los jóvenes se dan principalmente en torno a los medios de transmisión de la infección y aseguran que: «existe disonancia entre el apropiado nivel de conocimientos que poseen los jóvenes sobre cómo prevenir la transmisión del VIH y la presencia de comportamientos no adecuados al respecto, lo que concuerda perfectamente con la baja percepción de riesgo de contraer la enfermedad» (sp). Además de ello, Barella, Mesa y Cobeña (2002), refieren que: «la información sobre sexualidad que reciben los jóvenes suele ser desvirtuada y parcial, convirtiéndose en rutinaria o estereotipada» lo cual dificulta las prácticas sexuales saludables (p. 38).

El estudio realizado por Castillo et al., (2003), revela que la mayoría de la información que tienen los adolescentes (48\%) sobre el VIH/SIDA proviene del número de horas que dedican a ver televisión, leer el periódico y escuchar la radio, además señala que a medida que aumenta el curso y la edad del alumno, aumenta el nivel de conocimientos. A su vez Catacora \& Villanueva (2007), en su investigación confirman que la televisión es el medio principal de comunicación por el cual lo escolares reciben información sobre VIH, y hacen énfasis en la participación del internet como fuente importante de información. Sumado a esto, la investigación realizada por Uribe (2005), encontró que las habilidades y conocimientos en los adolescentes para la prevención del VIH/SIDA son insuficientes, dado que el saber de los jóvenes frente al virus y el síndrome de inmunodeficiencia adquirida, se encuentra en un nivel medio, y se relaciona específicamente con las formas de transmisión, prevención y evolución del virus.

Hallazgos importantes revelan que existen varias ideas erróneas sobre la forma de prevención y las vías de transmisión del VIH; entre las ideas que más prevalecen se encuentran: que la única manera de saber si se contrajo el virus es esperando a que se manifieste, que el sexo oral no es un medio por el cual se pueda transmitir el virus, que la infección puede transmitirse por la picadura de un mosquito, que el preservativo no protege y que dar un beso profundo puede ser un medio de transmisión (Vera, Sánchez \& Góngora, 2006; Machi, Benítez, Corvalán, Nuñez \& Ortigoza, 2008).

La autoeficacia es otra variable estudiada como riesgo para la infección de VIH/ SIDA en adolescentes. Este constructo ha sido definido por diversos autores, entre ellos Bandura $(1982,1997)$, quién expone que la autoeficacia representa «la evaluación de la propia habilidad o competencia para desempeñar una conducta especifica exitosamente, o como las creencias respecto a ser capaz de desempeñar exitosamente una conducta para lograr ciertos resultados»; sin embargo, otros autores como Choi (2004), Schwarzer y Scholz (2000), ampliaron el concepto, agregando que puede concebirse como «un sentido amplio y estable de competencia personal para afrontar exitosamente una variedad de situaciones desafiantes para el individuo» (p.6).Su importancia radica en que le permitirle a la persona desarrollar cursos de acción apropiados y utilizar las destrezas de forma indicada en las circunstancias difíciles (Ortega y García-Serrano, 2006). 
Se ha encontrado que «una persona que muestra confianza en sus habilidades para controlar su entorno y negociar actividades sexuales de menor riesgo, tiene mayores posibilidades de que la conducta de prevención se lleve a cabo» (Sterk, Klein, \& Elifson, 2003 citados por Pérez, 2009: 415). Incluso, la autoeficacia le permite al adolescente desarrollar habilidades orientadas a la ejecución de conductas saludables y protectoras, como el uso del preservativo, el rechazo de comportamientos de alto riesgo, el dialogo con su compañero sobre relaciones sexuales anteriores y riesgos vividos, entre otras (Bandura, 1997; Noboa y Serrano-García, 2006).

En cuanto a los métodos de prevención y protección Lozano, Torres y Aranda (2008), encontraron que los jóvenes identifican la capacidad de decisión y el uso del condón durante las relaciones sexuales como métodos preventivos ante las infecciones de transmisión sexual, lo cual puede estar relacionado con la autoeficacia. En esa medida, López y Moral (2001), agregan que a mayor autoeficacia, menor número de parejas sexuales y, a mayor edad, mayor autoeficacia percibida para usar el preservativo. Estas investigaciones demuestran que el nivel de percepción por parte del adolescente frente a su competencia para desarrollar una conducta sexual asertiva para prevenir el VIH, es determinante al momento de analizar los factores protectores en los jóvenes.

La susceptibilidad como variable presente en el análisis de las conductas protectoras o de riesgo en los adolescentes, juega un papel determinante ya que se refiere a «la percepción de riesgo que tiene una persona de las consecuencias negativas que podría generar la ejecución de una conducta determinada» (Onusida, 1999 citado por Uribe et al., 2009: 32). Una investigación hecha por Chirinos, Bardales y Segura (2006; citados por Uribe et al., 2009) sobre las relaciones coitales y la percepción de riesgo de adquirir ITS/SIDA en jóvenes, reveló que el $58 \%$ de los entrevistados creían que no presentaban riesgo de infectarse de alguna ITS, y sus razones principales fueron: tener pareja estable y ser fiel a ella (50\%), ausencia de relaciones sexuales (26\%) y sólo el 5,5\% señaló el uso continuo de preservativo.

Por otro lado, las actitudes son consideradas como un factor de riesgo para la infección por VIH/SIDA, a pesar de no garantizar la realización final de la conducta, sí predicen una mayor probabilidad de aparición de la misma. Espada, Quiles \& Méndez (2003) plantean que, «aunque la intención de llevar a cabo determinado comportamiento no es suficiente, si es necesaria para mantener comportamientos protectores» (p.34). Esto se evidencia en estudios donde la intención de usar preservativo en futuro contacto sexual, correlaciona positivamente con su uso (Goh, Primavera y Bartalini, 1996; Sheeran, Abraham y Orbell, 1999 citados por Espada, Quiles \& Méndez, 2003). Otros estudios exponen que las posturas de la sociedad, mitos o creencias transmitidas sobre el VIH/SIDA, pueden influir en la actitud que el adolescente asuma frente al manejo de su sexualidad y frente a las personas diagnosticadas (Vega y Lacoste, 1995). 
A modo de conclusión, estudiar y comprender las distintas variables que ponen en riesgo a los adolescentes frente a la adquisición del VIH/SIDA, se hace de suma importancia, no solo para conocer cómo se encuentran los jóvenes en relación a cada aspecto, si no también ampliar la visión sobre la importancia de diseñar e implementar programas que velen por una sexualidad sana y por el mantenimiento de conductas benéficas que le permitan al adolescente tener una mejor calidad de vida. Esta exploración de los factores de riesgo que precipitan la infección por VIH requiere ser estudiada y analizada desde diversos aspectos que resultan ser fundamentales para la comprensión de esta problemática, es por ello que en el presente trabajo de investigación se aplicó la adaptación Colombiana de la escala de VIH 65, creada originalmente por Paniagua (1998) y adaptada al Castellano por Bérmudez, Buela-Casal y Uribe (2005), en donde se tienen en cuenta las variables expuestas a lo largo del texto. Sin embargo, enfatizarse en estos aspectos no implica descuidar aquellos factores que pueden resultar importantes al momento de evaluar el comportamiento de los jóvenes, ya que como plantea Fajardo (2006), hay «otros atributos psicológicos que mediatizan la conducta: creencias religiosas, valores, motivaciones, actitudes, el nivel intelectual, etc.» (p.11).

\section{Método}

\section{Participantes}

En el estudio participaron 398 adolescentes de secundaria vinculados a instituciones educativas públicas y privadas de Bucaramanga y su área metropolitana, de los cuales el 42,2\% eran hombres, el 55\% mujeres y el 2,8\% restante no reportó género. La edad promedio fue de 14,50 años, con una desviación estándar de 1,354. Se realizó un muestreo probabilístico, de tipo aleatorizado y estratificado. Entre los criterios de inclusión se estableció el estar escolarizado, residiendo en zona urbana de Bucaramanga y su área metropolitana, con una edad no menor a 12 años y que cursaran del grado octavo en adelante.

\section{Instrumentos}

Cuestionario de información general (Uribe, Bermudez y Buela-Casal, 2005), incluye variables sociodemográficas como estrato socioeconómico, genero, edad, tipo de institución educativa, zona, jornada académica, nivel de escolaridad, región geográfica, departamento, municipio, el código de la institución y personas con las que vive actualmente. Así mismo evalúa algunos aspectos relacionados con la infección por VIH como las fuentes de información, transmisión y formas de prevención.

Escala VIH/Sida-65 (Paniagua,1998, adaptada por Bermúdez, Buela-Casal y Uribe, 2005), consta de 65 ítems y se divide en siete subéscalas: conocimiento correcto sobre el VIH/Sida (20 ítems), ideas erróneas sobre prevención y 
transmisión del VIH (20 ítems), actitudes negativas hacia personas con Sida (5 ítems), actitudes positivas sobre aspectos relacionados con el VIH /Sida (5 ítems), actitudes negativas hacia los preservativos (5 ítems), percepción de susceptibilidad para la infección por el VIH (5 ítems) y percepción de autoeficacia en el uso del preservativo ( 5 ítems). El análisis factorial confirma la estructura de la escala y un análisis de confiabilidad con un alfa de Cronbach 0,79 para el instrumento.

\section{Procedimiento}

Para el desarrollo de esta investigación, se realizaron diversas jornadas de investigación teórica que permitieron ampliar la documentación científica que actuaría como base para la exploración del tema, permitiendo identificar los instrumentos de investigación previamente descritos y que arrojaron los datos expuestos en el presente artículo. Una vez determinada la muestra y el plan de acción sobre el cual marcharía la investigación, se realizó un acercamiento a las instituciones educativas que participaron del estudio, con el propósito de explicar los fines inquirentes de la actividad evaluativa, presentar los instrumentos de investigación y la metodología de la aplicación (forma y tiempo).

\section{Resultados}

La muestra estuvo constituida por estudiantes de todos los estratos socioeconómicos; sin embargo, el estrato socioeconómico 3 demostró ser el correspondiente a la mayor concentración de adolescentes evaluados, alcanzando un porcentaje del $37,2 \%$, seguido del estrato 2 con un $27,3 \%$ y ocupando un tercer lugar el estrato 4 con un total del $18 \%$ de la muestra.

De la muestra trabajada, 168 estudiantes corresponden al género masculino $(43,4 \%)$ y 219 al género femenino $(56,6 \%)$.

La selección de las instituciones educativas se realizó de forma aleatoria, participaron 208 instituciones públicas $(52,4 \%)$ y 189 instituciones privadas (47,6\%) de Bucaramanga y su área metropolitana; el 100\% de las instituciones que participaron en la investigación se encuentran en zona urbana. Los resultados indican que la mayoría de los participantes están adscritos a la jornada de la mañana con un $81,4 \%$ y tan solo un $18,6 \%$ a la jornada de la tarde. En cuanto a la distribución de la muestra en relación al curso o grado académico mostró una participación mayor del grado octavo 50.5\% y decimo $41.5 \%$. El porcentaje restante se distribuyó en noveno $4.3 \%$ y undécimo $3.8 \%$. El municipio que reporta mayor porcentaje en la participación de la investigación es Floridablanca con un $44,7 \%$ y el de menor participación es el municipio de Piedecuesta con un $14,3 \%$. 
En cuanto al tema relacionado con la convivencia, del total de la muestra, el $56,0 \%$ señaló que vive con ambos padres y un $19.8 \%$ reporta vivir solo con la madre. Por su parte, un número considerable de estudiantes vive con sus padres o familiares y tan solo el $0,8 \%$ indicó que comparte vivienda con personas que no pertenecen a su base familiar.

El 70,6 \% de la muestra revela profesar la religión católica, seguido por la religión evangélica en un $11,1 \%$, protestantes con un 1,0\% y los musulmanes en $1,5 \%$, a su vez el 5,3\% refieren no pertenecer a ninguna religión, mientras que un $9,6 \%$ pertenecen a otras religiones. Los porcentajes más bajos pertenecen a la religión judía con un $0,3 \%$ y mormona con 0,5 . De los datos anteriores, la muestra puntúa en relación a la práctica de la religión de la siguiente manera: en un $49.4 \%$ señala que práctica un poco la religión y un $37,7 \%$ reporta ser practicante, solo un $12,9 \%$ reporta no ser practicante de su religión.

Por otra parte, un $65,2 \%$ de la población evaluada reporta no tener conocimiento de padecer alguna enfermedad, en contraste, el $34.1 \%$ reporta si tener conocimiento de padecer alguna enfermedad.

El medio que se destaca por ser el mayor canal de información de los estudiantes con respecto a la transmisión del VIH son los programas de television con un $25 \%$, seguido por la familia en un $23 \%$, amigos o conocidos en $17 \%$ y charlas en el colegio con un 16\%. Los estudiantes reportan haber recibido información sobre los métodos de prevención y las formas de transmisión de la siguiente manera: un $72,9 \%$ de los estudiantes reporta haber recibido información sobre prevención del VIH mientras que un 27,1\% reporta no haber recibido ningún tipo de información sobre prevención. Por otro lado, el $56.8 \%$ de los estudiantes reporta haber recibido información sobre la trasmisión del VIH y el 42,9\% reporta no haber recibido ninguna clase de información al respecto. En esta misma línea, el medio que se destaca por ser el mayor canal de información de los estudiantes con respecto a la prevención del VIH son los programas de televisión en un $30 \%$, seguido de la familia en un $22 \%$, las charlas en el colegio un $18 \%$ y amigos o conocidos un $17 \%$.

A continuación se exponen los resultados del análisis descriptivo, en donde se destacan los ítems más representativos según cada subescala.

\section{Subescala de conocimientos correctos e incorrectos frente al VIH/Sida}

Los resultados encontrados dentro de esta subescala evidencian que en la población entrevistada existe gran desconocimiento en cuanto a las características propias del VIH/SIDA; así lo demuestran el 38.9\% de los adolescentes entrevistados quienes manifiestan su desconocimiento frente a la afirmación de que en la actualidad no hay cura conocida para el VIH y el $23.2 \%$ plantea no tener conocimiento frente al hecho de que el SIDA debilita la capacidad del cuerpo para combatir otras enfermedades. 
De igual forma, el desconocimiento prevalece en torno al tema que concierne a los medios de transmisión y prevención, en donde el $42.2 \%$ de la población planteó no saber que una persona puede estar infectada con el virus y no presentar ningún síntoma de la enfermedad, información que se complementa con las afirmaciones: «las personas pueden tener el virus del SIDA en su cuerpo y no estar enfermos» y «se puede contraer el SIDA a través de alguien que está infectado aunque no manifiesta ningún síntoma de la enfermedad» cuyos resultados arrojaron un $41.7 \%$ y un $33.5 \%$ (respectivamente) de adolescentes que expresan no tener conocimiento sobre estos hechos.

Finalmente, en lo que respecta a la transmisión del virus por medio de la relación sexual, el $35.7 \%$ de la población entrevistada no sabe si es posible que el virus se transmita entre dos hombres que tengan relaciones sexuales y el $33.4 \%$ desconoce si se puede contraer el virus a través de la penetración anal. Por tanto, la predominancia en el desconocimiento frente a los factores previamente enunciados, se constituye como factor de riesgo para la población adolescente entrevistada.

En lo que respecta a la subescala de conocimientos incorrectos, se evidencia que la muestra a la que ha sido aplicada la prueba tiene ideas equívocas especialmente frente a dos circunstancias; la primera de ellas se manifiesta en la predisposición que se tiene de contraer el virus dentro de las relaciones homosexuales y la segunda constituye la adquisición del virus compartiendo utensilios de uso personal y lugares públicos. Dentro de los ítems más representativos en esta subescala, encontramos que el $79,74 \%$ de los adolescentes plantea que la enunciación en donde se indica que todas las personas con el virus del SIDA son homosexuales, es falsa. A esta afirmación se suma la de creer que todas las mujeres que tienen relaciones con otras mujeres tienen el virus, en la que el porcentaje representa el desconocimiento en un $52,16 \%$.

Por otra parte, en cuanto a los ítems que evalúan la adquisición del virus por medio de utensilios de uso personal encontramos que el 59,7\% de los adolescentes manifiestan que es posible contraer el virus al compartir cuchillos, tenedores o vasos con una persona infectada. Así mismo, el 32,8\% de esta población considera que se puede contraer el virus del SIDA bebiendo de la misma taza o vaso que una persona infectada uso. En cuanto a la afirmación sobre que si se puede contraer el virus del SIDA por los asientos de los baños públicos, el $32,0 \%$ de los adolescentes respondieron que esto es verdadero y al referirnos a la afirmación de que se contraer el virus por medio de un teléfono público que ha sido utilizado por alguien infectado, los adolescentes en un porcentaje del $42,13 \%$ manifiestan su desconocimiento. 


\section{Subescala de autoeficacia frente al VIH/Sida}

Los resultados arrojados por la investigación y que conciernen a esta escala, demuestran que respecto a las prácticas sexuales se evidencia un acuerdo del $40.3 \%$ en cuanto a la capacidad para adquirir preservativos con facilidad, un $69.1 \%$ en cuanto a la capacidad de preguntar a la pareja si ha tenido relaciones sexuales con alguien que se prostituya, un $70.4 \%$ en cuanto a la capacidad de llevar consigo un preservativo en caso de tomar la decisión de tener relaciones sexuales, sin embargo se registra un $20,61 \%$ dice que no sabe si se siente capaz de cargar el preservativo.

\section{Subescala de Susceptibilidad frente al VIH/Sida}

En cuanto a la susceptibilidad, se encontró que el 76\% de la población manifiesta sentirse preocupado por la posibilidad de contraer SIDA. Sin embargo, solo un $36.6 \%$ de los adolescentes entrevistados asegura ser susceptible ante la infección, al señalar como falso el ítem «no soy el tipo de persona que pueda contraer el virus» al expresar su acuerdo frente a tal afirmación, por otro lado el $34 \%$ plantea no saber si puede adquirir el VIH.

\section{Subescala de actitudes frente a la infección por VIH/Sida}

La actitud positiva en la población entrevistada evidencia que los adolescentes asumen posiciones de aceptación frente a las personas portadoras del virus; así lo demuestra el 45,3\% de la población que expuso su acuerdo frente a la afirmación de que debería permitirse a las personas con SIDA el uso de buses públicos, un $34 \%$ que plantea que debería permitirse a las personas infectadas con el virus vivir en unidades residenciales y un $46,3 \%$ que dice estar desacuerdo con que estas personas asistan a clase, sin embargo, en esta última afirmación aparece un $27,63 \%$ de la población que contrasta tal idea demostrando su oposición y un $25,9 \%$ que dice no tener conocimiento sobre esta afirmación.

En cuanto a la actitud negativa se encontró que un $55.5 \%$ expresa estar en desacuerdo frente a la afirmación de que no se sentaría al lado de una persona diagnosticada con SIDA, un 50.1\% que plantea estar en desacuerdo con aislar a las personas portadoras del SIDA para garantizar la seguridad de los demás y un $53.5 \%$ que opina estar en desacuerdo con el hecho de aislar constantemente a los portadores del VIH de los demás. Sin embargo, el $61 \%$ de la población, manifiesta su incomodidad en relación a compartir las mismas prendas de vestir o compartir el mismo baño con una persona infectada.

Los resultados encontrados en actitud neutra revelan que el desconocimiento de los estudiantes frente a ciertas afirmaciones pueden constituir riesgo, Así lo evidencia el $80.6 \%$ de la población, cuando afirma que es importante usar condón, cada vez que se tengan relaciones sexuales, sin embargo la cifra de 
quienes plantean no tener dificultad para conseguir condones fácilmente se reduce al $29.4 \%$ de la población entrevistada.

Finalmente, se exponen los resultados de los conocimientos correctos, conocimientos incorrectos, las actitudes (positivas, negativas y neutras), la susceptibilidad y la autoeficacia frente a la infección por el VIH en función del género. Las medias y las desviaciones típicas de las variables dependientes medidas los conocimientos correctos, conocimientos incorrectos, actitud positiva, actitud negativa, actitud neutra, susceptibilidad y autoeficacia se representan de manera comparativa. La representación gráfica de las medias de las variables que tienen diferencias significativas puede verse a continuación.

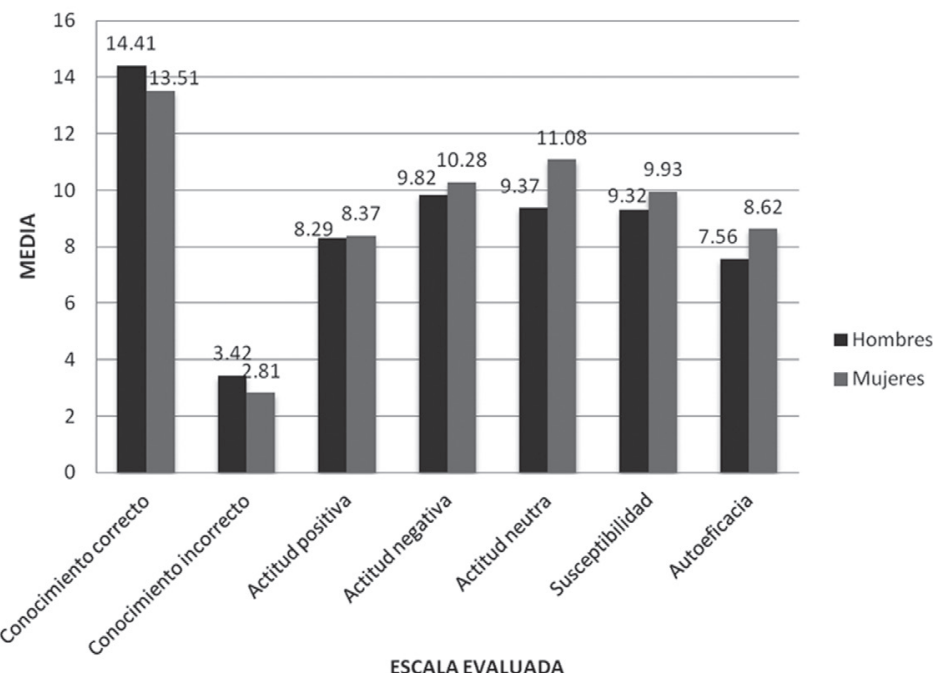

Gráfica 1. Medias de los conocimientos correctos e incorrectos, actitud negativa, actitud neutra, autoeficacia y susceptibilidad sobre la infección por el VIH/SIDA en adolescentes colombianos en función del género.

El análisis realizado indica diferencias significativas en función del género en conocimientos correctos $\mathrm{F}_{(1,351)}=6,411 ; \mathrm{MSE}=11,211 ; p<0,012$, conocimientos incorrectos $\mathrm{F}_{(1,346)}=3,951 ; \mathrm{MSE}=7,956 ; p<0,048$, las actitud negativa $\mathrm{F}_{(1,380)}=4,432$; $\mathrm{MSE}=4,463 ; p<0,036$, en la actitud neutra $\mathrm{F}_{(1,369)}=59,242 ; \mathrm{MSE}=4,493 ; p<0,000$, en la susceptibilidad $\mathrm{F}_{(1,369)}=9,067 ; \mathrm{MSE}=3,721 ; p<0,003 \mathrm{y}$ en la autoeficacia $\mathrm{F}_{(1,364)}=17,906 ; \mathrm{MSE}=5,653 ; p<0,000$ (Tabla 1). Las mujeres presentan mayor nivel de actitud negativa, neutra y mayor susceptibilidad y autoeficacia que los hombres. Por el contrario, los hombres presentan mayores conocimientos correctos e incorrectos que las mujeres. No existen diferencias significativas en la actitud positiva en función del género. Estos datos se recogen en la tabla 1. 


\begin{tabular}{|c|c|c|c|c|}
\hline Escalas & gl & $\begin{array}{c}\text { Media } \\
\text { cuadrática }\end{array}$ & $\mathbf{F}$ & Sig \\
\hline Conocimiento correcto & 1 & 11,211 & 6,411 & 0,012 \\
\hline Conocimiento incorrecto & 1 & 7,956 & 3,951 & 0,048 \\
\hline Actitud positiva & 1 & 5,867 & 0,089 & 0,765 \\
\hline Actitud negativa & 1 & 4,463 & 4,432 & 0,036 \\
\hline Actitud neutra & 1 & 4,493 & 59,242 & 0,000 \\
\hline Susceptibilidad & 1 & 3,721 & 9,067 & 0,003 \\
\hline Autoeficacia & 1 & 5,653 & 17,906 & 0,000 \\
\hline
\end{tabular}

Tabla 1. Grados de libertad, media cuadrática, $F$ y nivel de significancia del conocimiento correcto, conocimiento incorrecto, actitud positiva, actitud negativa, actitud neutra, susceptibilidad y autoeficacia sobre la infección por el VIH/SIDA de los adolescentes colombianos en función del género.

\section{Discusión}

El panorama actual global de la situación del VIH, tiene sus fundamentos en el desconocimiento predominante de los adolescentes en el mundo, de ahí que las cifras más preocupantes se hayan identificado en la población que se encuentra entre los 14 y 25 años.

En consecuencia, los resultados hallados en la presente investigación actúan como prueba, al demostrar que el conocimiento que prevalece en la población adolescente Santandereana tiene soporte en un saber incorrecto, hecho que se ha corroborado en diversas investigaciones (Cortés, García, Fullerat y Fuentes, 2000; Castillo, Estremera, León \& Naranjo, 2003; González, Núñez, Couturejuzon y Amable Ambrós, 2005), a pesar de los esfuerzos realizados a través de los años por las diferentes organizaciones que promueven programas de prevención del VIH/SIDA y promoción de conducta sexual y reproductiva responsable. De esta forma, en la muestra evaluada se registra con alta frecuencia, que el desconocimiento gira en torno a los medios de transmisión y métodos de prevención frente al VIH y otras enfermedades de transmisión sexual, principalmente en afirmaciones específicas como que el virus tiene preferencia por las personas que mantienen relaciones homosexuales, que se puede transmitir compartiendo utensilios personales como el cepillo, la ropa, vasos y cubiertos, y compartiendo espacios públicos como baños, habitaciones y piscinas. Estas y otras ideas equívocas son predisposiciones que elevan los factores de riesgo para contraer VIH y ETS; no obstante, los adolescentes invierten sus esfuerzos 
en prevenir cierto tipo de conductas que consideran importantes en cuanto a la infección y descuidan aquellas que finalmente son las principales causas de la propagación de la enfermedad. Es importante recalcar que estas actitudes identificadas en los adolescentes pueden estar justificadas en la creencia de que la infección tiene cura, como lo aseguran algunos de los individuos evaluados, quienes a su vez transmiten esa idea incorrecta como hecho real.

Referente a las actitudes en relación al VIH/SIDA se encontró que los adolescentes se autoperciben con actitud positiva frente a las personas portadoras del virus, afirmando que se debe aceptar, permitir y promover la inclusión de estas personas en la sociedad, posibilitando que ellas hagan parte de conjuntos residenciales, instituciones educativas y sociales; información que se confirma en el análisis de la actitud negativa de los evaluados, al señalar como falsas, las afirmaciones que indican que sería pertinente aislar a los portadores de la sociedad y que no se deberían compartir espacios públicos con ellos. Se presume que adoptar una actitud positiva frente a las personas afectadas por el virus orienta a los adolescentes hacia la ejecución de conductas de protección; así lo plantean Bimbela y Gómez (1994), citados por Espada, Quiles y Méndez (2003), quienes a su vez argumentan que «las actitudes de los individuos que han vivido más cerca del problema del SIDA a través de un familiar o de un conocido, suelen tener unas actitudes más racionales y basadas en una información más objetiva sobre la realidad» (p.35). Por otra parte, la actitud neutra se presenta de forma incongruente cuando la mayoría de los adolescentes participantes manifiestan su acuerdo sobre la importancia del uso del condón en cada relación sexual y sin embargo, solo un pequeño porcentaje de la población evaluada aseguró que no tiene dificultad para conseguirlo, información que se contrapone más adelante en el análisis de la autoeficacia percibida por el adolescente; es importante tener en cuenta que «las actitudes no garantizan la realización final de una conducta, pero si predicen una mayor posibilidad de aparición» (Espada et al., 2003: 34), por consiguiente la prevalencia de esta disonancia presente en los adolescentes, podría significar en el momento de la relación sexual una conducta de protección (en el primer caso), o bien una conducta de riesgo (en el segundo caso).

Por otra parte, los adolescentes se perciben en su mayoría autoeficaces, al afirmar que serían capaces de controlar el uso del condón al momento de la relación sexual, a través de la exigencia, porte y uso del mismo. De igual forma, un gran porcentaje de la población asegura que es capaz de llevar consigo el condón, por si se presenta la oportunidad de tener una relación sexual. Estos hallazgos pueden considerarse como factor protector de los adolescentes, ya que «en la medida en que la autoeficacia se incremente, el uso del preservativo se vuelve más frecuente» (Basen-Engquist y Parcel, 1992, citados por Uribe, 2005: 81 ), sin embargo, hacer esta interpretación no es garantía de que las conductas protectores prevalecerán en la mayoría de los individuos, es así como Uribe, Valderrama, Sanabria, Orcasita y Vergara (2009), plantean que «la autoeficacia puede o no presentarse en ciertas poblaciones» (p.40) y lo explican en términos de 
que en ocasiones el número de adolescentes que se abstienen de tener relaciones sexuales disminuye significativamente en relación al número de adolescentes que se sienten totalmente o muy capaces de usar el condón.

Por su parte, la susceptibilidad arrojó datos relevantes en torno a la percepción que tienen los adolescentes frente a la vulnerabilidad para infectarse, ya que la mayoría manifiesta sentir preocupación ante la posibilidad de adquirir el virus, información que no corresponde con las afirmaciones de Espada et al. (2003), cuando plantea que «como resultado de los importantes avances en los tratamientos médicos, se ha disminuido la percepción de riesgo de infectarse» y adiciona que para el 2003 «las tendencias epidemiológicas apuntaban al colectivo heterosexual como el más propenso a nuevas infecciones, y las prácticas sexuales sin protección como la principal vía de transmisión» (p.35), lo cual es un indicador de que la baja percepción de susceptibilidad también puede estar sujeta a conocimientos incorrectos y baja autoeficacia.

Finalmente, el análisis inferencial realizado arrojó datos significativos en función del género, en donde se demuestra que la población femenina posee mayores capacidades de autoprotección que la masculina. Datos comprobados a través del significado de las variables evaluadas y del análisis individual que se realizó de cada una de ella y que se desarrolló detenidamente a lo largo del artículo. El ministerio de protección social en el 2010 publicó que la prevalencia del VIH en Colombia, es mayor en los hombres, datos que corroboran las revelaciones halladas en la investigación y los análisis efectuados.

\section{Referencias bibliográficas}

Bandura, A. 1997. Self-Efficacy. The Exercise of Control. New York: Freeman.

Bandura, A. 1982. Self-Efficacy mechanism in human agency. American psychology, 2: 122-147.

Barella, J., Mesa, I. \& Cobeña, M. 2002. Conocimientos y actitudes sobre sexualidad de los adolescentes de nuestro entorno. Medicina de Familia, 3: 255-260.

Bermúdez, M., Buela-Casal, G. \& Uribe, A. 2005. Adaptación al colombiano de la escala VIH-65. Universidad de Granada. Documento sin publicar.

Bretón, J. \& Buela-Casal, G. 2005. Evaluación del efecto las campañas publicitarias de prevención de VIH/SIDA en adolescentes. Psicothema, 17: 590-596.

Caballero Hoyos, R. \& Villaseñor-Sierra, A. 2003. Conocimientos sobre VIH/SIDA en adolescentes urbanos: consenso cultural de dudas e incertidumbres. Salud Pública de México, 45: 108-114. 
Castillo Sánchez, M.D., Gil Extremera, B., León Espinosa de los Monteros, M.T. \& Naranjo Rodríguez, J.A. 2003. Conocimiento de los escolares sobre SIDA. Revista SMEG Sociedad Española de Médicos Generales y de Familia, 51: 109-120.

Castillo Sánchez, M.D., Gil Extremera, B., Naranjo Rodríguez, J.A. \& León Espinosa de los Monteros, M.T. 2001. Actitudes de los escolares hacia enfermos de sida. Medicina General, 37: 705-710.

Catacora López, F. \& Villanueva Roque, J. 2007. Conocimientos sobre VIH/SIDA y prácticas sexuales de escolares de Tacna, Perú 2004. Revista Peruana de Medicina Experimental y Salud Pública, 24: 240-247.

Cortés Alfaro, A., García Roche, R., Fullerat Alfonso, R. \& Fuentes Abreu, J. 2000. Instrumento de trabajo para el estudio de las enfermedades de transmisión sexual y VIH/ SIDA en adolescentes. Revista Cubana de Medicina Tropical, 52 (1): 48-54.

Choi, N. 2004. Sex role group differences in specific, academic, and general self-efficacy. The Journal of Psychology, 138: 149-159.

Chirinos, J. L., Bardales, O. y Segura, M.D. 2006. Las relaciones coitales y la percepción de riesgo de adquirir ETS/SIDA en adultos jóvenes varones de Lima, Perú. Cuadernos de SaludPública, 22: 79-85.

Espada Sánchez, J.P., Quiles Sebastián, M.J. \& Méndez Carillo, F.J. 2003. Conductas sexuales de riesgo y prevención del SIDA en la adolescencia. Papeles del Psicólogo, 24: 29-36.

Fajardo, E. 2006. Conocimientos y comportamientos sexuales en torno al VIH-SIDA en la población de estudiantes de pregrado en la universidad Santa María la Antigua. Invent. Pens.Crit. 4: 3-12.

Fuertes, A., Martínez, J. L., Ramos, M., de la Orden, V. y Carpintero, E. 2002. Factores asociados a las conductas sexuales de riesgo en la adolescencia. Infancia y Aprendizaje, 25: 347-361.

González, J.C. 2009. Conocimientos, actitudes y prácticas sobre la sexualidad en una población adolescente escolar. Revista de Salud Pública, 11: 14-26.

Gonzáles Gonzáles, F.G. 2004. Conocimientos, actitudes y prácticas en salud sexual y reproductiva en jóvenes entre 14 y 25 años de edad de estratos 1 y 2 del Sisben de un municipio del departamento de Cundinamarca. Acta Colombiana de Psicología, 12: 5968.

González Valcárcel, B., Nuñez Aragón, E., Couturejuzon González, L. \& Amable Ambrós, Z. 2005. Conocimientos y comportamientos sobre VIH/SIDA en adolescentes de enseñanza media superior. Revista Cubana Salud Pública, online, 34(2). 
López-Rosales, F. \& Moral- de la Rubia, J. 2001. Validación de una escala de autoeficacia para la prevención del Sida en Adolescentes. Salud Publica México, 43: 421-432.

Lozano, A., Torres, T. \& Aranda, C. 2008. Concepciones culturales del VIH/SIDA de estudiantes adolescentes de la Universidad de Guadalajara, México. Revista Latinoamericana Ciencias Sociales, Niñez y Juventud, 6 (2): 739-768.

Macchi, M.L., Benítez, S., Corvalán, A., Nuñez, C. \& Ortigoza D. 2008. Conocimientos, actitudes y prácticas acerca del VIH/SIDA en jóvenes de nivel medio de educación del área metropolitana, Paraguay. Archivo de Pediatría del Uruguay, 79: 253-263.

Ministerio de la Protección Social. 2010. Informe UNGASS - Seguimiento de la declaración de compromiso sobre el VIH/SIDA. República de Colombia, 1-146.

Navarro, E. \& Vargas, R. 2004. Conocimientos, actitudes y prácticas sobre el SIDA en adolescentes escolarizados. Salud Uninorte, 19: 14-24.

Noboa, P. y Serrano-García, I. 2006. Autoeficacia en la negociación sexual: retos para la prevención de VIH/SIDA en mujeres puertorriqueñas. Revista Latinoamericana de Psicología, 38: 21-43.

Onusida. 2011. Informe de Onusida para el dia mundial del SIDA. Programa conjunto de las naciones unidas sobre el VIH/SIDA, 1-52.

Onusida. 2010. Informe sobre la epidemia mundial del sida. Programa conjunto de las naciones unidas sobre el VIH/SIDA, 1-62.

Onusida 1999. Infección por VIH y SIDA en Colombia: 1999. Aspectos fundamentales, respuesta nacional y situación actual. Un balance histórico hacia el nuevo siglo. Bogotá: Onusida.

Ortega Noboa, P. \& García-Serrano, I. 2006. Autoeficacia en la negociación sexual: Retos para la prevención del VIH/SIDA en mujeres puertorriqueñas. Revista Latinoamericana de Psicología, 38: 21-43.

Pérez-Jiménez, D., Santiago-Rivas, M. \& Serrano-García, I. 2009. Comportamiento sexual y autoeficacia para la negociación de sexo más seguro en personas heterosexuales. Revista Interamericana de Psicologia/Interamerican Journal of Psychology, 43: 414-424.

Schwarser, R. \& Scholz, U. 2000. Cross-cultural assessment of coping resources: The General Perceived self-Eficcacy scale. Trabajo presentado en el Primer Congreso Asiático de Psicología de la Salud. Tokyo.

Uribe, A. F. 2005. Evaluación de factores psicosociales de riesgo para la infección por el VIH/SIDA en adolescentes Colombianos. Tesis Doctoral. Granada (España): Universidad de Granada, Departamento de Personalidad, Evaluación y Tratamiento Psicológico. 
Uribe, A.F., Bermúdez, M.P. \& Buela-Casal, G. 2005. Cuestionario General. Universidad de Granada. Documento sin publicar.

Uribe R, A.F., Valderrama, L., Sanabria, A.M., Orcasita, L. \& Vergara, T. 2009. Descripción de los conocimientos, actitudes, susceptibilidad y autoeficacia frente al VIH/ SIDA en un grupo de adolescentes Colombianos. Pensamiento Psicológico, 12: 29-44.

Vega Fuente, A. y Lacoste Marín, J.A. 1995. Niños y adolescentes y SIDA: Problemática psicosocial e intervención educativa. Valencia: Promolibro.

Vera-Gamboa, L., Sánchez- Magallón, F, \& Góngora-Biachi, R.A. 2006. Conocimientos y percepción de riesgo sobre el Sida en estudiantes de bachillerato de una universidad pública de Yucatán, México: un abordaje cuantitativo cualitativo. Revista Biomédica, 17: 157-168. 